\title{
Equipotentiality of Thalamo-Amygdala and Thalamo-Cortico- Amygdala Circuits in Auditory Fear Conditioning
}

\author{
Lizabeth M. Romanski and Joseph E. LeDoux \\ Center for Neural Science, New York University, New York, New York 10003
}

The goal of the present study was to examine the contribution of thalamo-amygdala and thalamo-cortico-amygdala projections to fear conditioning. Lesions were used to destroy either the thalamo-cortico-amygdala projection, the thalamo-amygdala projection, or both projections, and the effects of such lesions on the acquisition of conditioned fear responses (changes in arterial pressure and freezing behavior) to a tone paired with footshock were measured. In each group of animals examined, a large lesion of the acoustic thalamus, including all nuclei of the medial geniculate body and adjacent portions of the posterior thalamus, was made on one side of the brain to block auditory transmission to the forebrain at the level of the thalamus on that side. In this way, experimental lesions could be made on the contralateral side of the brain. Thus, animals with thalamo-amygdala pathway lesions received a large lesion of the acoustic thalamus on one side. Contralaterally, only the nuclei that project to the amygdala (the medial division of the medial geniculate body, the posterior intralaminar nucleus, and the suprageniculate nucleus) were selectively destroyed, leaving much of the thalamo-cortico-amygdala projection intact. For thalamo-cortico-amygdala pathway lesions, the acoustic thalamus was destroyed on one side and temporal and perirhinal cortices were ablated contralaterally. In these animals, thalamo-amygdala projections were intact on the side of the cortical lesion. Destruction of either pathway alone had no effect on auditory fear conditioning. However, combined lesions of the two sensory pathways disrupted conditioning. Thus, auditory conditioned stimulus (CS) transmission to the amygdala is necessary in fear conditioning but either thalamo-amygdala or thalamo-cortico-amygdala projections are sufficient as CS transmission routes.

Classical fear conditioning depends upon the transmission of auditory conditioned stimulus (CS) information to the lateral nucleus of the amygdala (AL) (LeDoux et al., 1990b). AL receives inputs from auditory processing areas of the thalamus and cortex. Auditory thalamo-amygdala projections originate

\footnotetext{
Received Nov. 6, 1991; revised May 26, 1992; accepted June 12, 1992.

This work was supported by U.S. Public Health Service Grants MH38774 and MH46516. This work was partially conducted at Cornell University Medical College and fulfilled part of the requirements of Lizabeth Romanski's Ph.D. at that institution.

Correspondence should be addressed to Lizabeth M. Romanski, Yale University School of Medicine, Section of Neurobiology, 333 Cedar Street, New Haven, CT 06511.

Copyright (C) 1992 Society for Neuroscience $0270-6474 / 92 / 124501-09 \$ 05.00 / 0$
}

in the medial division (MGm) of the medial geniculate body (MGB), the posterior intralaminar nucleus (PIN), and the suprageniculate nucleus (SG) (Veening, 1978; Ottersen and BenAri, 1979; Turner and Herkenham, 1981, 1991; Russchen, 1982; LeDoux et al., 1985, 1990a, 1991; Kudo et al., 1989). In the rat, these posterior thalamic areas each receive inputs from the inferior colliculus and project to AL (LeDoux et al., 1987, 1990a). Auditory thalamo-cortical projections arise from these same thalamic nuclei, as well as from ventral (MGv) and dorsal (MGd) divisions of the MGB, and terminate in temporal neocortex and perirhinal periallocortex (Lashley, 1941; Locke, 1961; Jones and Powell, 1971; Niimi and Naito, 1974; Killackey and Ryugo, 1975; Patterson, 1977; Winer et al., 1977; Deacon et al., 1983; Diamond, 1983; Vaughan, 1983; LeDoux et al., 1984, 1985 , 1991; Winer and Larue, 1987; Scheel, 1988; Roger and Arnault, 1989; Arnault and Rogcr, 1990; Romanski, 1991; for review, see Kelly, 1990). Temporal neocortical and perirhinal periallocortical regions, in turn, project to the amygdala (Whitlock and Nauta, 1956; Jones and Powell, 1970; Herzog and Van Hoesen, 1975; Aggleton et al., 1980; Turner et al., 1980; Guldin and Markowitsch, 1983; Turner and Zimmer, 1984; Amaral, 1987; McDonald and Jackson, 1987; Kudo et al., 1989; LeDoux el al., 1991; Romanski, 1991). Thus, auditory information, including auditory $\mathrm{CS}$ information, may reach the $\mathrm{AL}$ via thalamo-amygdala or thalamo-cortico-amygdala projections.

Previous studies have shown that auditory fear conditioning, in rats, is not blocked by bilateral ablation of the auditory cortex (LeDoux et al., 1984), even when posterior perirhinal cortex is included (Romanski and LeDoux, 1992), but is interfered with by bilateral lesions of the MGB and adjacent nuclei of the posterior thalamus (LeDoux et al., 1984, 1986), bilateral lesions of the amygdala (Kapp et al., 1979; Gentile et al., 1986; Hitchcock and Davis, 1986; LeDoux et al., 1990b), or disconnection of the amygdala from auditory processing areas of the thalamus (Iwata et al., 1986; LeDoux et al., 1986). These findings indicate that cortico-amygdala projections are not necessary and that thalamo-amygdala projections are sufficient as auditory CS transmission routes to the amygdala during fear conditioning. However, these findings leave unanswered whether thalamoamygdala projections are necessary and whether cortico-amygdala projections are sufficient as CS transmission routes.

The goal of the present study was to examine further the contribution of thalamo-amygdala and thalamo-cortico-amygdala projections to fear conditioning. Lesions were used to interrupt either the auditory thalamo-amygdala pathway (selective lesions of only those thalamic regions that receive inputs from the inferior colliculus and send afferents to the amygdala), the thalamo-cortico-amygdala pathway (complete auditory cortex lesions), or both pathways. The effect of these lesions on the 


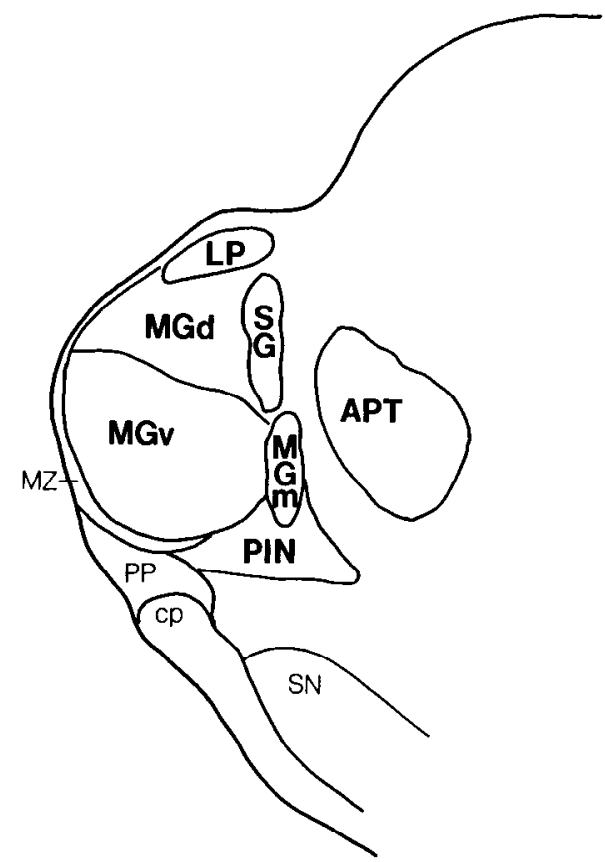

Figure 1. The rat MGB and associated nuclei of the posterior thalamus. Major auditory nuclei are shown in boldface. Thalamo-amygdala projections originate from MGm, PIN, and SG, while thalamo-cortical projections originate from these as well as the MGv and MGd. $A P T$, anterior pretectal nuclcus; $c p$, ccrcbral peduncle; $L P$, lateral postcrior nucleus; $M Z$, marginal zone; $P P$, peripeduncular nucleus; $S N$, substantia nigra.

acquisition of conditioned fear responses was measured. On the basis of previous studies, we hypothesized that either (1) interruption of thalamo-amygdala projections alone, but not interruption of cortico-amygdala projections, would interfere with conditioning, or (2) destruction of neither pathway alone would interfere with conditioning but destruction of both pathways together would. If destruction of the thalamo-amygdala pathway disrupts conditioning, we would conclude that thalamo-amygdala projections are a necessary and sufficient CS transmission route. However, if destruction of neither pathway alone interferes with conditioning, but combined lesions of the two pathways do, we would conclude that while neither pathway is neccssary, cach is sufficient.

\section{Materials and Methods}

\section{Animals}

Studies were performed using male Sprague-Dawley rats (Hilltop Laboratories), which weighed $300-350 \mathrm{gm}$ at the start of the experiments The animals were housed individually in clear plastic cages and had free access to laboratory chow and water. The housing area was thermally controlled, sealed to sunlight, and maintained on a fluorescent light cycle ( 0700 on, 1900 off). All experiments were conducted during the light phase of the cycle.

\section{Surgery}

Stereotaxic placement of lesions. One week after their arrival, animals were anesthetized with pentobarbital $(40 \mathrm{mg} / \mathrm{kg})$ and placed in a stereotaxic frame. Lesions were made either electrolytically or by subpial aspiration. All surgeries were performed under aseptic conditions.

Lesions were made to accomplish the following goals. (1) To destroy completely the acoustic thalamus, defined as those areas of the thalamus that receive inputs from the inferior colliculus (see LeDoux et al., 1987): these lesions included the ventral, dorsal, and medial divisions of the medial geniculate body (MGB), as well as PIN, SG, and other regions of the posterior thalamus. The divisions of the MGB (Fig. 1) in the rat (LeDoux et al., 1985, 1987; Winer and Larue, 1987; Clerici and Coleman, 1990) are classified in a manner similar to the widely accepted scheme of Morest and Winer for the cat (Morest, 1964, 1965, 1975; Morest and Winer, 1986) and opossum (Winer et al., 1988). PIN and SG in the rat (LeDoux et al., 1985, 1986; Paxinos and Watson, 1986) are based on parcellation schemes in opossum (Rockel et al., 1972; Neylon and Haight, 1983; Winer et al., 1988). (2) To destroy selectively only those thalamic areas that both receive inputs from the inferior colliculus and project to AL (see LeDoux et al., 1987, 1990a): these lesions included the medial division of the medial geniculate body (MGm), PIN, and SG. (3) To destroy completely the auditory cortex, which was defined in the most liberal fashion possible on the basis of studies of axonal transport from the MGB (LeDoux et al., 1985; Winer and Larue, 1987; Roger and Arnault, 1989; Clerici and Coleman, 1990; Romanski, 1991) and includes neocortical areas TE1, TE2, and TE3 of Zilles (Zilles et al., 1980, 1990; Zilles and Wree, 1985) and perirhinal periallocortex (Turner and Zimmer, 1984).

Large lesions of the acoustic thalamus (MGB lesions) were made by passing anodal constant current ( $1 \mathrm{~mA}, 15-17 \mathrm{sec}$ ) through a monopolar, stainless steel electrode $(200 \mu \mathrm{m}$ diameter) insulated with epoxylite to within $500 \mu \mathrm{m}$ of the tip. Lesion placement was guided by an atlas of the rat brain (Paxinos and Watson, 1986). The anterior, posterior, mediolateral, and dorsoventral coordinates were computed relative to the interaural line (AP 2.9, ML 3.3, DV 3.3).

Lesions of MGm, PIN, and SG were made by passing anodal constant current $(100 \mu \mathrm{A}, 7-9 \mathrm{sec})$ through a stainless steel wire $(0.005$ in diameter) coated with Teflon to within $500 \mu \mathrm{m}$ of the tip. Coordinates were: AP 3.0, ML 3.0, DV 3.3 and AP 3.6, ML 2.8, DV 3.1.

For auditory cortex lesions, the skull covering temporal neocortex was removed and an incision was made in the dura. Ablation of ventral auditory cortex was accomplished by placing six electrolytic lesions along the anterior-posterior extent of the rhinal fissure (AP 1.8, ML 6.4, DV 2.8; AP 3.0, ML 6.8, DV 2.5; AP 4.5, ML 6.8, DV 2.6; AP 6.0, ML 6.7, DV 2.8), using the parameters described above for lesions of the acoustic thalamus. Then, dura was reflected back and dorsal temporal neocortex was aspirated. Bleeding was controlled with Gelfoam or gauze. The dura was then resutured (when possible). Controls were either unoperated or given unilateral lesions of the acoustic thalamus.

Upon completion of all surgeries, the wound was closed and bacteriostatic ointment was applied. The animal was placed into its home cage under a heat lamp. Once awake, the animal was returned to the housing area. Body weight, food and water intake, and general health were routinely monitored.

Chronic catheterization for recording arterial pressure. After 14-21 d recovery from stereotaxic surgery, a catheter was implanted in the left carotid artery (Talman et al., 1980; LeDoux et al., 1984, 1985, 1986, 1990b; Iwata et al., 1986). Animals were anesthetized with Aerrane (Anaquest, $2-4 \%$ in $100 \%$ oxygen). An incision was made in the neck on the ventral surface and the tissues were retracted, exposing the left carotid artery. A plastic (Tygon) cannula ( 0.015 inch i.d.) filled with $0.9 \%$ saline containing heparin $(100 \mu \mathrm{l} / \mathrm{ml})$ was inserted into the thoracic aorta via the left common carotid artery. Its tip was placed at the level of the diaphragm. The distal end of the left carotid was occluded. The free end of the cannula was fixed to the soft tissues with sutures and passed subcutaneously through an incision behind the head at the back of the neck. The neck wound was sutured around the cannula, anchoring it in place, and the cannula was sealed with a stainless steel plug. Upon recovery from the anesthesia, the animal was returned to the housing area. The cannula was flushed daily with $0.5 \mathrm{ml}$ of heparinized saline.

\section{Behavioral procedures}

Classical conditioning. Details of the conditioning and testing procedures have been previously published (LeDoux et al., 1984, 1986, 1990b). Briefly, all rats were conditioned 14-21 d following stereotaxic surgery and $24 \mathrm{hr}$ after chronic catheterization. Animals were removed from their home cages and placed individually in a rodent conditioning chamber (Coulbourn Instruments, E10-10) enclosed in a sound-attenuating shell (Coulbourn Instruments, E10-20). The conditioned stimulus (CS) was an $800 \mathrm{~Hz}$ tone produced by a frequency generator (Coulbourn Instruments, S81-06), amplified to $80 \mathrm{~dB}$ (Archer Mini Amplifier), and presented for $10 \mathrm{sec}$ through a speaker mounted on the side panel of the conditioning chamber. The unconditioned stimulus (US) consisted of a brief $(500 \mathrm{msec})$ pulse of direct current $(2.5 \mathrm{~mA})$ produced by a 
A

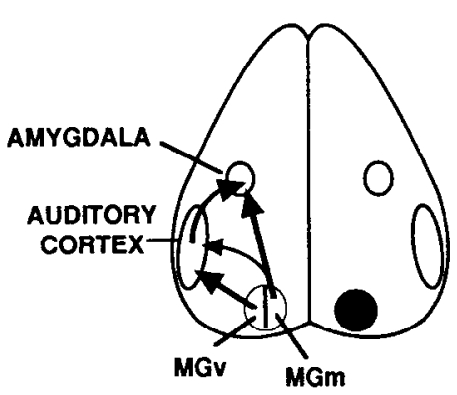

B

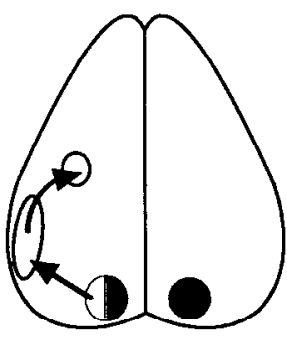

C

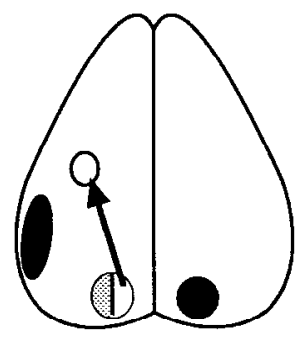

D

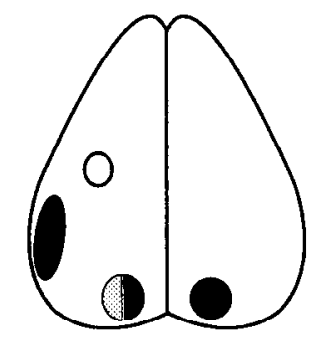

Figure 2. Schematic diagram of the lesion strategy used to examine auditory pathways involved in fear conditioning. During auditory fear conditioning, sensory information can reach the amygdala via two pathways. In $A$, the thalamo-amygdala pathway is a monosynaptic relay that originates in MGm, PIN, and SG, while the thalamo-cortico-amygdala pathway is a polysynaptic route through auditory cortex that originates in several areas of the posterior thalamus including $\mathrm{MGv}$ and $\mathrm{MGm}$. Large lesions of the acoustic thalamus were made unilaterally in $A-D$ (shown as the solid circle on the right), interrupting transmission to the amygdala on that side, so that the effects of experimental lesions could be evaluated contralaterally. $A$, A unilateral lesion of the acoustic thalamus on the right still allows transmission of auditory CS information to the amygdala contralaterally via thalamo-amygdala and thalamo-cortico-amygdala pathways. $B, \mathrm{MGm}, \mathrm{PIN}$, and SG lesions block thalamo-amygdala projections but still allow CS transmission via thalamo-cortico-amygdala projections on the same side. $C$, Auditory cortex lesions block cortico-amygdala projections but allow CS transmission via thalamo-amygdala projections on the same side. The stippling in MGv indicates retrograde degeneration. $D$, Combined auditory cortex plus MGm, PIN, and SG lesions blocks CS transmission through both thalamo-amygdala and thalamo-corticoamygdala pathways.

grid floor shocker (Coulbourn Instruments, E13-08) and distributed across the grid noor.

Stimulus presentation was controlled by a microprocessor (IBM-XT) equipped with a digital output board (Opto 22). During the classical conditioning session, the auditory CS was presented alone for the first 10 trials, and for the next 30 trials the final $500 \mathrm{msec}$ of the CS was concurrent with the footshock US. For a pseudoconditioned control group, the US occurred randomly with respect to the CS. The intertrial interval was $150 \mathrm{sec}$ on the average (range, 100-200 sec). Following the training session, which lasted $103 \mathrm{~min}$, the animal was returned to its home cage and transferred to the housing area.

Assessment of conditioned responses. Conditioned responses (CRs) were tested in the presence of the CS during extinction trials (no US), approximately $24-28 \mathrm{hr}$ after classical conditioning. Testing was conducted either in the animal's home cage or in a separate test box, similar to the conditioning box but lacking a grid floor. The autonomic response consisted of a stimulus-locked increase in arterial blood pressure (LeDoux et al., 1984; Iwata and LeDoux, 1988). The behavioral change measured was the crouching or "freezing" response induced by presentation of the CS (Blanchard and Blanchard, 1972; Fanselow and Bolles, 1979; Bouton and Bolles, 1980; LeDoux et al., 1984). The arterial blood pressure and freezing responses differ in animals given paired presentations of the CS and US versus animals given random, unpaired presentations of the CS and US and thus reflect associative learning processes (Iwata et al., 1986; LeDoux et al., 1986; Iwata and LeDoux, 1988).

To examine arterial prcssure responses, the animals were placed in the test box and the arterial cannula was connected to a strain-gauge transducer (Stratham P23Db), which rested outside the box at the level of the animal's heart. Pulsatile and mean arterial blood pressure were digitized at $100 \mathrm{~Hz}$ and continuously recorded on a computer based system that allowed a second-by-second reconstruction of the blood pressure recording.

After connecting the cannula to the strain-gauge transducer, approximately 15 min was allowed for the animals to acclimate to the testing apparatus. When blood pressure had stabilized, the CS was presented. The presentation schedule of the CS by the microprocessor was the same as during the conditioning trials except that experimenter intervention was possible. If an animal moved excessively or blood pressure was unsteady during the pre-CS baseline period, the trial was aborted and restarted when a steady baseline was reachcd. Artcrial blood pressure was recorded continuously throughout the $10 \mathrm{sec} C S$, and for the 10 sec immediately preceding and following the CS. Three extinction trials were presented and averaged together. After the trials, the animal was returned to its home cage and given food and water.
Approximately $2 \mathrm{hr}$ after the arterial pressure test, freezing in the presence of the CS was measured. The animal was placed into the test box (see above). This procedure elicits a high level of exploratory activity (Bouton and Bolles, 1980; LeDoux et al., 1984). After approximately 15 sec of continuous aclivity, the CS was presented and the amount of freezing during the $120 \mathrm{sec}$ test period was measured with a stopwatch.

\section{Histology}

Upon completion of the behavioral studies, the animals were given an overdose of sodium pentobarbital $(120 \mathrm{mg} / \mathrm{kg})$ and perfused transcardially with $0.9 \%$ saline followed by $10 \%$ buffered formalin. The brains were postfixed in formalin and later frozen and sectioned on a sliding microtome at $40 \mu \mathrm{m}$. Every fourth section was collected and mounted onto acid-cleaned, gelatin-subbed slides, and stained with thionin $(0.25 \%)$. Lesion location was plotted using camera lucida or a projection microscope.

\section{Results}

To assess the contributions of thalamo-amygdala and thalamocortico-amygdala pathways to fear conditioning, an asymmetric lesion strategy was used (Iwata et al., 1986; LeDoux et al., 1986). In each lesion group, the entire acoustic thalamus, defined as the projection field of the inferior colliculus (LeDoux et al., 1987), was lesioned in one hemisphere and the experimental lesion was made contralaterally. Using this strategy, auditory information transmission to the forebrain was interrupted at the level of the thalamus on the side of the large thalamic lesion (Fig. $2 A$ ) and the effects of the contralateral, experimental lesions wcre sclectively assessed without the necessity of making bilaterally symmetric lesions (Iwata et al., 1986; LeDoux et al., 1986). Five groups of animals were examined. One group of animals received unilateral lesions of the acoustic thalamus (UMG group). In these animals, auditory information can reach the amygdala on the intact side by way of either thalamo-amygdala or thalamo-cortico-amygdala projections (Fig. $2 A$ ). A second group of animals (MGm group) received lesions of MGm, PIN, and SG on one side and large thalamic lesions contralaterally (Fig. 2B). In these animals, the thalamo-amygdala projection is destroyed on the experimental side by the MGm, PIN, and SG lesions, 
Figure 3. Photomicrographs of typical thalamic and cortical lesions. Two cases are shown to illustrate all of the various lesion combinations. Four lesion groups were examined: UMG, MGm, ACX, and ACX + MGm. $A$, Thalamo-amygdala. Animals in this group received lesions of $\mathrm{MGm}, \mathrm{PIN}$, and SG on one side (right side, curved arrow) and lesions of the entire acoustic thalamus contralaterally (left side, straight arrow). B, Combined thalamoamygdala and thalamo-cortico-amygdala lesion. On the right side, auditory cortex (arrowheads) and MGm, PIN, and SG (curved arrow) are lesioned, while the entire acoustic thalamus is lesioned contralaterally (left side, straight arrow). The cortical lesion included all areas within TE1, TE2, TE3, and posterior perirhinal periallocortex. Arrowheads delimit the dorsal and ventral aspects of the cortical ablations. Animals in the ACX group received the same cortical ablations, shown in $B$, on one side and a lesion of the acoustic thalamus contralaterally. UMG animals received only a lesion of the acoustic thalamus on one side.
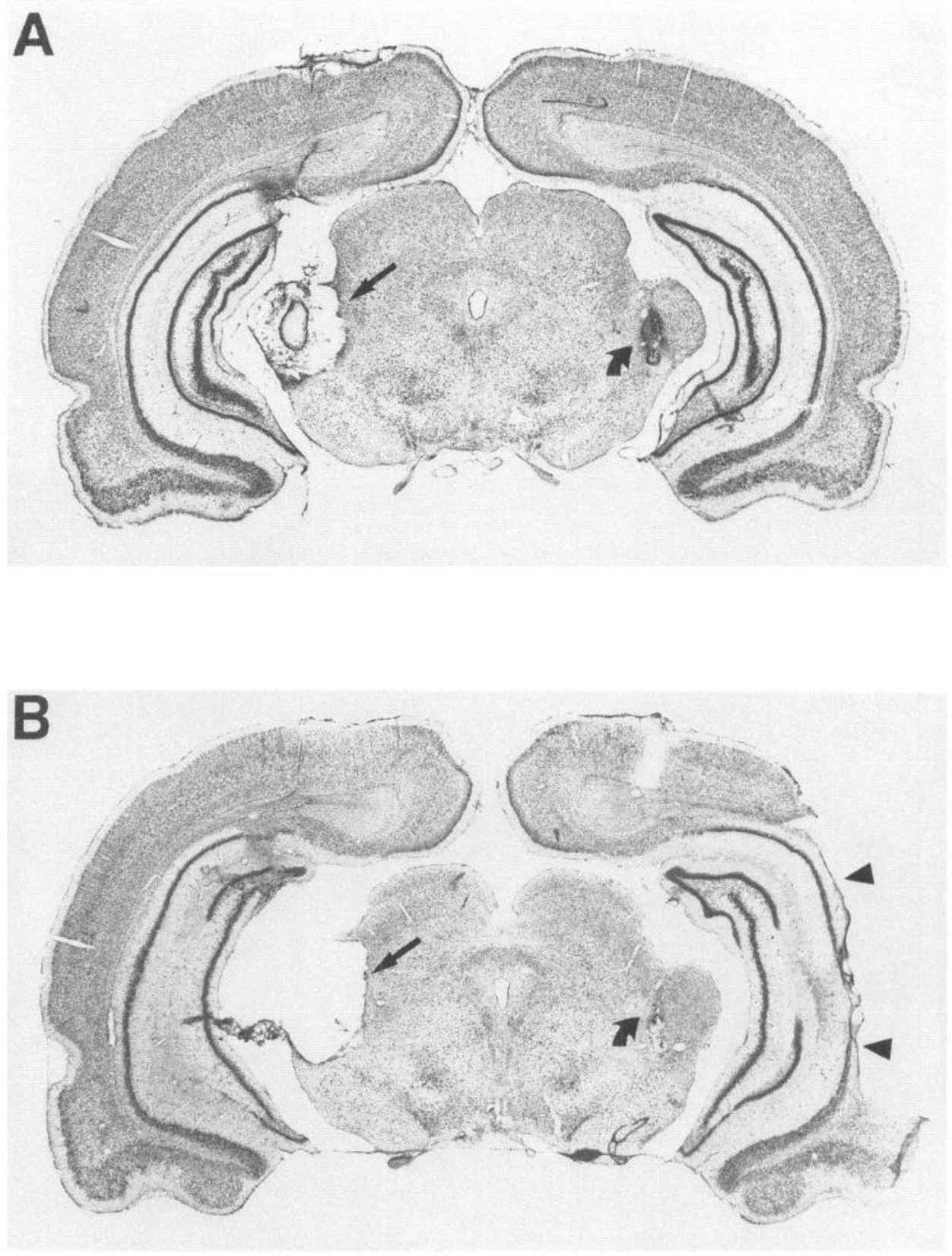

but auditory information can still reach the amygdala by way of projections from intact thalamic areas, particularly MGv and MGd, which project to temporal and perirhinal cortex, which in turn project to the amygdala. The third group consisted of animals with unilateral lesions of auditory cortex and large thalamic lesions contralaterally (ACX group). This lesion combination eliminates thalamo-cortico-amygdala transmission but allows thalamo-amygdala transmission on the side of the auditory cortex lesion (Fig. 2C). In the fourth group, lesions of MGm, PIN, and SG were combined with auditory cortex lesions on the same side (ACX + MGm group), destroying both thalamo-amygdala and cortico-amygdala pathways on that side (Fig. $2 D$ ). As in other groups, a large thalamic lesion was made contralaterally. A group of unoperated controls $(n=11)$ was also tested.

\section{Histological observations}

As stated previously, the experimental lesions were made unilaterally and the acoustic thalamus was lesioned contralaterally. In each lesion group, the contralateral lesion of the acoustic thalamus included damage to all subnuclei of the MGB, as well as adjacent regions of the posterior thalamus including PIN, SG, the peripeduncular region, and the medial posterior nucleus. In most cases, the brachium of the inferior colliculus as it enters the MGB was also ablated. Damage to the rostral one-third of the MGB varied, as did the extension of the lesion medially into the midbrain and thalamus.

Animals with lesions of MGm, PIN, and SG $(n=7)$ showed extensive damage to MGm and PIN as well as damage to the caudal most portions of SG and the medial posterior nucleus 
of the thalamus (Fig. $3 A$ ). In a few cases, the most rostral portions of SG and the posterior nucleus of the thalamus were spared.

Animals with auditory cortex lesions that were acceptable ( $n$ =6) exhibited damage to all of temporal neocortex, including areas TE1, TE2 and TE3, as well as caudal perirhinal periallocortex. In each case, TE1 and TE3 were completely destroyed (Fig. 4). In some cases there was minor sparing of TE2, especially the most caudal portion. This caudal aspect of TE2 appears to be, at least in part, a visual association area (Kolb, 1990). Since the aspiration lesions destroyed the portion of the external capsule that provides the fiber innervation of caudal TE2, this small surviving area was disconnected from the rest of the brain. In fact, there was severe retrograde chromatolysis in this region. In most auditory cortex lesions, the damage extended beyond auditory cortex, into parietal cortex. Also, in some cases there was unilateral damage to the dorsal most portion of the amygdala, but in no case was there bilateral amygdala damage. Extensive retrograde degeneration of ventral MGB was observed in all animals with auditory cortex lesions. MGm, PIN, and SG neurons survive auditory cortex lesions, presumably because of their subcortical projections (LeDoux et al., 1984).

In the ACX + MGm group $(n=7)$, each of the lesions was evaluated separately according to the criteria discussed above (Fig. 3B). Reconstruction of a typical combination lesion is depicted in Figure 5.

\section{Effects of lesions on fear conditioning}

Unoperated controls, UMG, MGm, and ACX lesioned animals all showed typical increases in arterial pressure and freezing behavior at the onset of the CS (Fig. 6). However, arterial pressure responses and freezing responses were greatly reduced in the ACX + MGm group. The arterial pressure responses of unoperated controls, UMG, MGm, and ACX lesioned animals increased at the onset of the CS and reached its peak at the third second of the CS (Fig. 6, left). ACX + MGm lesioned animals did not exhibit a large pressor response to the CS.

To analyze the autonomic CRs, an overall two-way ANOVA with one repeated measure was conducted. The factors were lesion group and time (seconds $1-10$ of the CS). The lesion group effect was significant $[F(4,41)=3.844 ; p=0.01]$, as was time $[F(9,369)=40.63 ; p<0.001]$ and the interaction of lesion group and time $[F(36,369)=1.940 ; p<0.001]$. Post hoc analysis with the Tukey test determined that the ACX + MGm group differed from all other groups. This effect was significant $(p<0.01)$ at seconds 3 and 4 of the CS (Fig. 6, left, stars). In fact, ACX + MGm lesioned animals exhibited autonomic responses to the CS that did not differ from that of animals given unpaired presentations of the CS and US (pseudoconditioned) $[F(1,12)=0.130$, NS; Fig. 7].

Animals with combined lesions of both pathways also differed from all other groups with respect to freezing. While unoperated (UNOPER) MGm, ACX, or UMG groups exhibited a high amount of freezing, ACX + MGm lesioned animals did not (Fig. 6, right). Statistical analysis of freezing (one-way ANOVA) revealed a significant lesion effect $[F(4,41)=11.77 ; p<0.001]$, and the Tukey test indicated that the ACX + MGm group was significantly different $(p<0.001)$ from all other groups, which did not differ from one another (Fig. 6, right).

Animals with lesions of either the thalamo-amygdala pathway (MGm group) or thalamo-cortico-amygdala pathway (ACX group) showed emotional CRs. However, the responses were
A

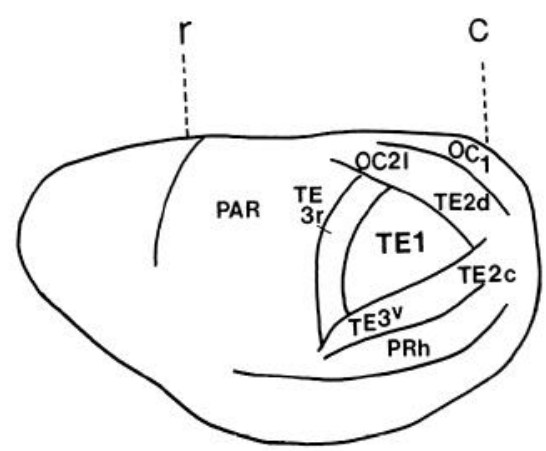

B

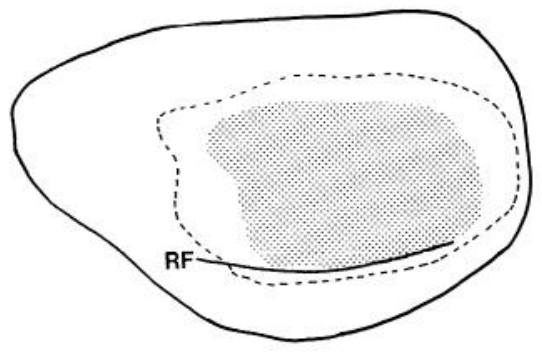

C

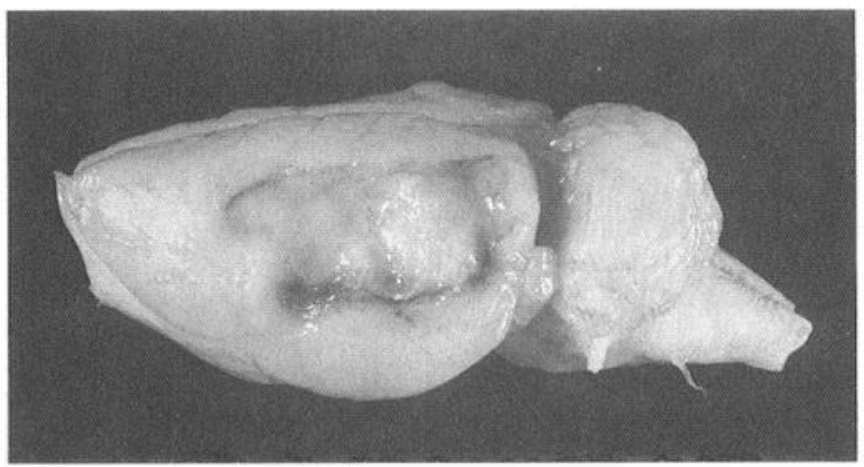

Figure 4. Schemata of the rat cerebral cortex, lateral view. A, Schematic diagram of auditory cortical regions in the rat. The parcellation of temporal cortex into TE1, TE2, and TE3, and their subregions, is based on Zilles et al., (1990) and findings from Romanski and LeDoux (unpublished observations), and is consistent with other parcellation schemes of the rat auditory cortex (Krieg, 1946; Patterson, 1977; Zilles and Wree, 1985; Herbert et al., 1991). A $c$ marks the location of the most caudal coronal section depicted in Figure 5; an $r$ indicates the location of the most rostral section in Figure 5. B, Lateral view of the location and size of auditory cortical lesions used in this study. The smallest lesions that were acceptable in this study encompassed the stippled area. The largest cortical lesion is indicated by the broken line. $R F$, rhinal fissure. $C$, Auditory cortex lesion, lateral view. A photomicrograph of a typical lesion of the auditory cortex is shown. Damage to all of TE1 and TE3 is present as well as damage to rostral TE2 and the caudal two-thirds of perirhinal periallocortex. Animals in the ACX group and animals in the ACX $+\mathrm{MGm}$ group received lesions of the auditory cortex identical to the one depicted.

greatly reduced in animals with damage to both thalamo-amygdala and thalamo-cortico-amygdala pathways ( $\mathrm{ACX}+\mathrm{MGm}$ group). These results demonstrate that either thalamo-amygdala or thalamo-cortico-amygdala pathways are sufficient as sensory transmission systems in classical fear conditioning using a simple auditory stimulus as a CS. 
Figure 5. Thalamo-amygdala + thalamo-cortico-amygdala lesion, caudal to rostral extent. A combined ACX + MGm lesion is depicted in its full caudorostral extent in coronal sections. On the left, the auditory cortical lesion reveals damage to temporal and perirhinal cortex as well as parietal cortical regions. The stippled areas on the left side (curved arrows) indicate the $\mathrm{MGm}$, PIN, and SG lesions, ipsilateral to the cortical lesion, and a lesion of the acoustic thalamus is depicted with stippling on the right side (straight arrows).

\section{CAUDAL}

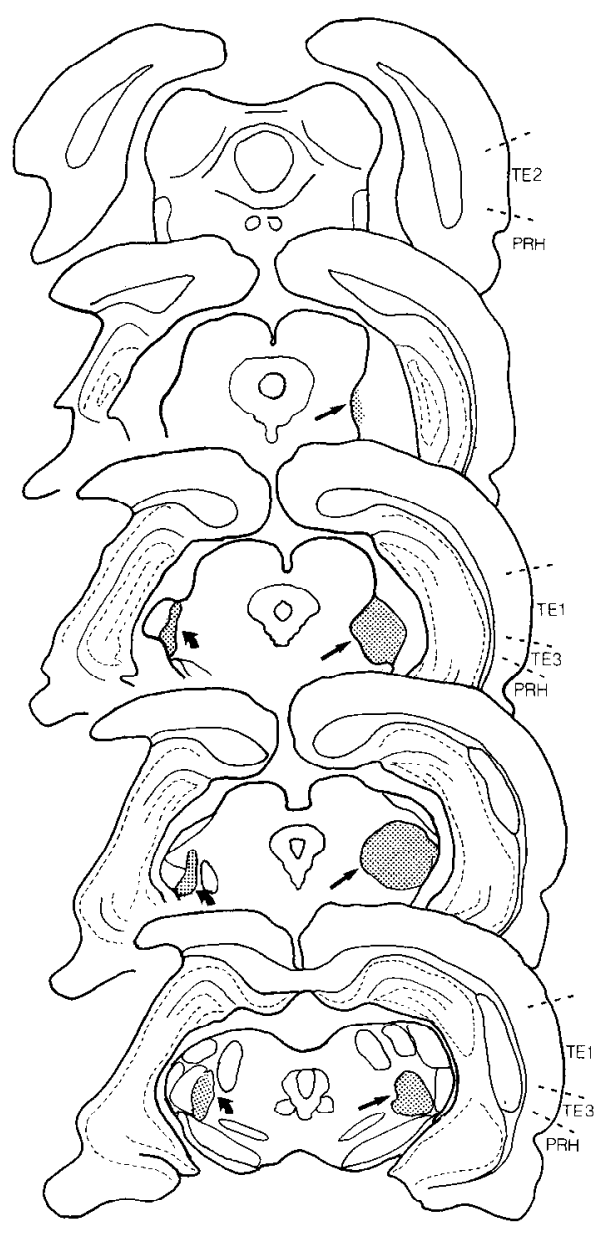

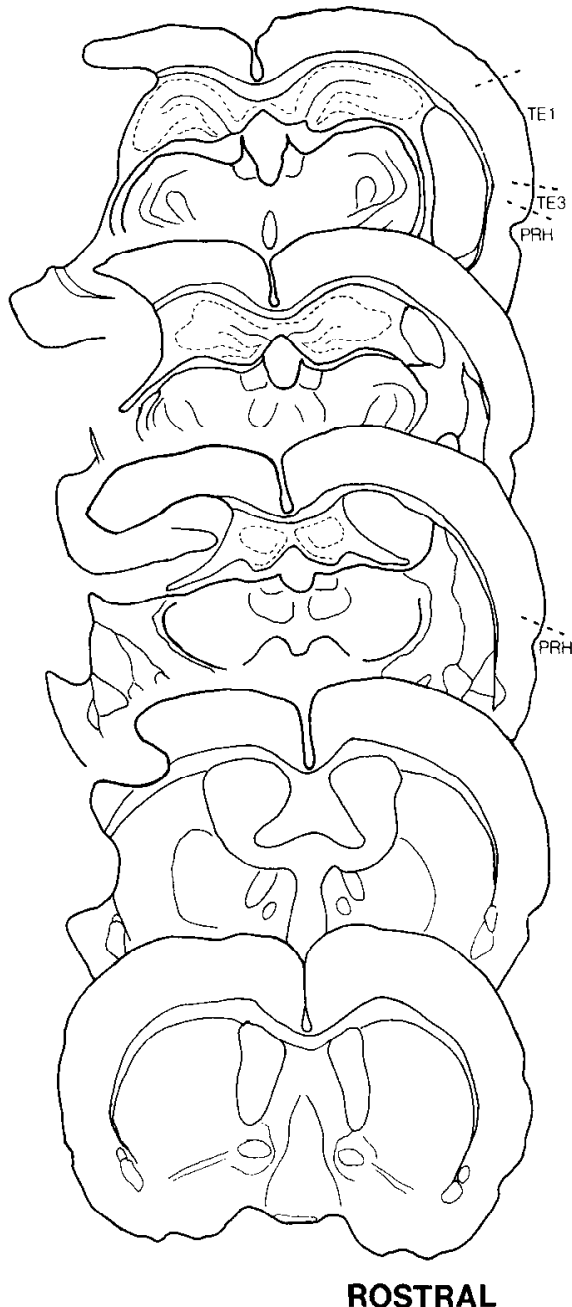

Figure 6. Effects of thalamo-amygdala and thalamo-cortico-amygdala pathway lesions on auditory fear conditioning. Combined lesions of both pathways (ACX + MGm group; $n=7$ ) interfere with autonomic (blood pressure) and behavioral (freezing) responses, while lesions of either the thalamo-cortico-amygdala (ACX group; $n$ $=9$ ) or thalamo-amygdala pathway (MGm group; $n=7$ ) do not disrupt conditioned responding compared with unoperated (UNOPER; $n=11$ ) or unilateral thalamic (UMG group; $n=12$ ) lesioned controls. Animals in the unoperated, UMG, ACX, and MGm groups showed increases in blood pressure (depicted on the left graph) at the onset of the $10 \mathrm{sec} C S$. In contrast, animals in the combination lesion group $(\mathrm{ACX}+\mathrm{MGm})$ exhibited greatly reduced blood pressure responses $(\star, p<$ 0.001 ). The amount of freezing (right graph), in response to the CS, of animals with combined lesions of both pathways (ACX + MGm group) was also significantly lower than that of all other groups $(\star, p<0.001)$.
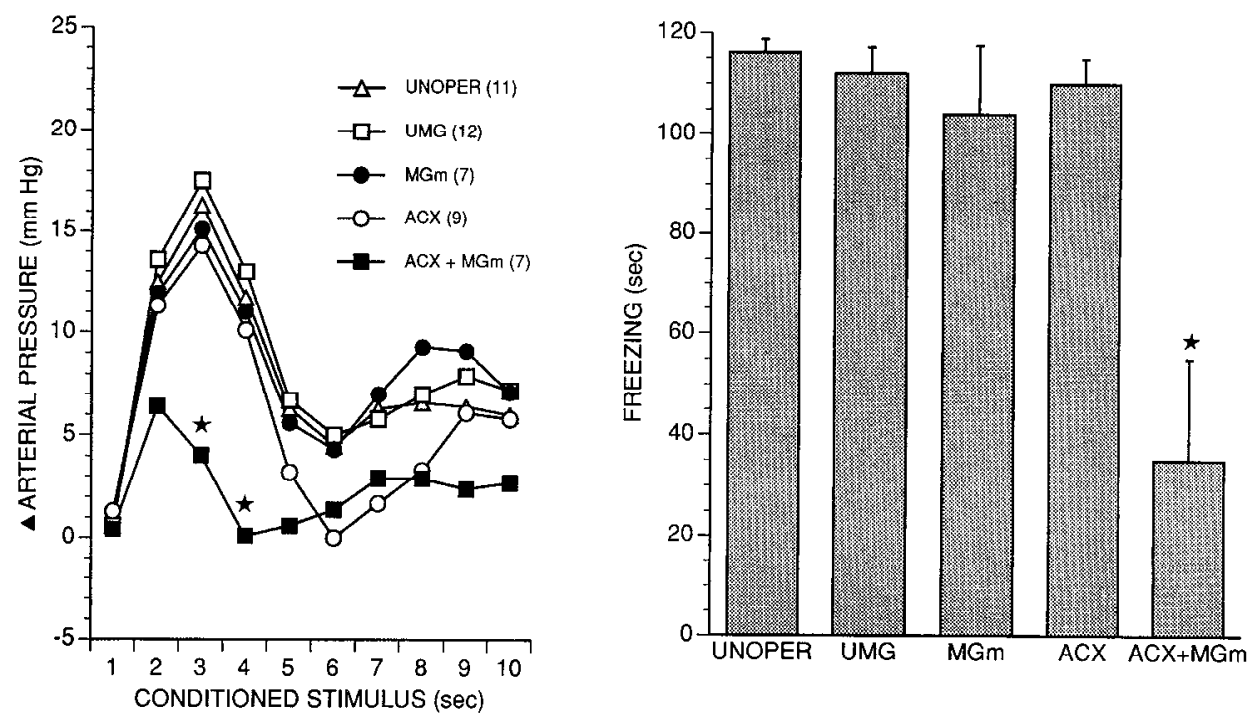


\section{Discussion}

The present study demonstrates the equipotentiality of thalamoamygdala and thalamo-cortico-amygdala pathways in mediating auditory fear conditioning. Thus, lesions of either the thalamo-amygdala pathway or the thalamo-cortico-amygdala pathway do not interfere with fear conditioning but combined lesions of both pathways severely impairs conditioning. Auditory CS transmission to the amygdala is essential in auditory fear conditioning but either thalamo-amygdala or thalamo-cortico-amygdala pathways are sufficient as CS transmission routes at least for conditioning tasks using a simple, undiscriminated CS.

Our results confirm previous findings that lesions of auditory cortex do not disrupt auditory fear conditioning to a simple CS (Goldberg and Neff, 1961; DiCara et al., 1970; LeDoux et al., 1984) even when all temporal and perirhinal cortical areas that receive afferents from the acoustic thalamus are destroyed (Romanski and LeDoux, 1992). In contrast, a recent study (Rosen et al., in press, cited in Sananes and Davis, 1992) found that lesions of perirhinal cortex interfered with fear CRs. However, that study examined the effects of perirhinal cortical lesions on the retention rather than the acquisition of the CR. Thus, perirhinal and other cortical areas may play a role in long-term storage of emotional memory.

Although forebrain auditory projections to the amygdala are required for the associative conditioning of autonomic responses, nonassociative responses utilize different pathways. This is indicated by the fact that pseudoconditioned responses elicited by the CS are unaffected even when both thalamo-amygdala and thalamo-cortico-amygdala CS transmission pathways are damaged. Since nonassociative autonomic responses also remain after lesions of the MGB or the inferior colliculus (LeDoux et al., 1984), such responses are probably mediated by direct connections between brainstem auditory nuclei and autonomic control regions.

Thalamo-amygdala and thalamo-cortico-amygdala CS transmission routes originate in different regions of the acoustic thalamus and probably have different processing capabilities and functions. The acoustic thalamus, as defined here, includes thalamic nuclei that receive inputs from the inferior colliculus. In the rat, these nuclei are the MGv, MGd, and MGm, as well as several areas of the posterior thalamus, including PIN and SG (LeDoux et al., 1985, 1987). Physiological studies, conducted mostly in cats, have shown that neurons in the MGv are tonotopically organized and narrowly tuned and respond with short latencies to acoustic stimuli (Aitkin and Dunlop, 1969; Aitkin and Webster, 1972; Aitkin, 1973; Calford and Webster, 1981; Calford, 1983). In contrast, neurons in other areas of the MGB and in the posterior thalamus tend to be more broadly tuned (Aitkin and Dunlop, 1969; Aitkin, 1973; Calford, 1983), with somc cclls also responding to somatosensory stimuli (Poggio and Mountcastle, 1960; Wepsic, 1966; Love and Scott, 1969).

Various schemes have been proposed to classify these auditory and other sensory processing areas of the thalamus: specific versus nonspecific (Lorente de No, 1938), lemniscal versus extralemniscal (Morrison and Dempsey, 1942; Nauta and Kuypers, 1958), lemniscal versus lemniscal adjunct (Graybiel, 1973), main sensory versus associated sensory versus unaligned (Winer and Morest, 1983). The scheme of Winer and Morest (1983) has the advantage of recognizing the diversity of possible sensory representations in the thalamus. In the auditory system, the

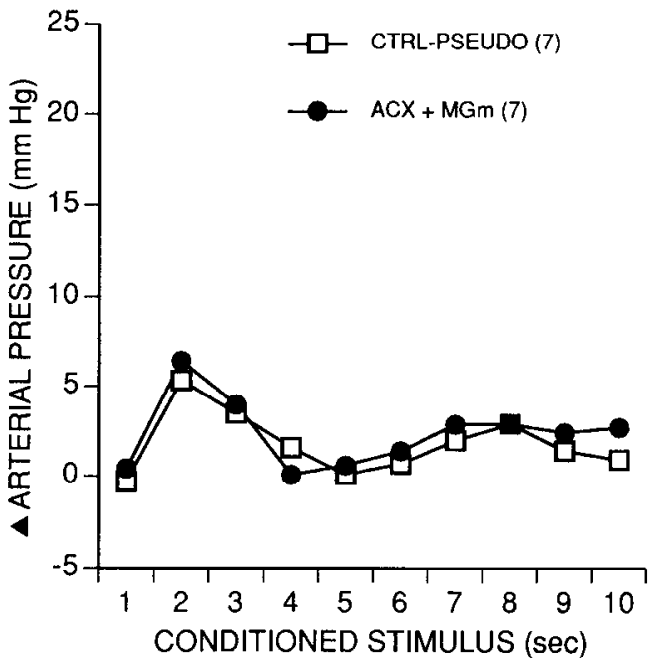

Figure 7. Animals with combined lesions of the thalamo-amygdala and thalamo-cortico-amygdala pathway ( $\mathrm{ACX}+\mathrm{MGm}$ group; $n=7$ ) show autonomic CRs that are similar to those of unoperated animals (CTRL-PSEUDO group; $n=7$ ) given random presentations of the CS and US (pseudoconditioned). Such nonassociative responses are probably mediated by connections between brainstem auditory and autonomic nuclei.

main sensory nucleus is the MGv, whereas the other divisions of the MGB and adjacent areas of the posterior thalamus, such as PIN and SG, constitute the associated and unaligned nuclei. Thalamo-cortico-amygdala auditory projections originate from main sensory, associated, and unaligned thalamic nuclei, whereas thalamo-amygdala auditory projections originate from associated and unaligned nuclei. The auditory thalamo-amygdala projection can therefore be viewed as a subset of the thalamocortical system since it originates in the associated and unaligned nuclei of the acoustic thalamus. As a result, the thalamo-amygdala systcm has a somewhat limited processing capacity compared to the thalamo-cortico-amygdala system, which capitalizes on the additional processing capabilities of main sensory thalamic nuclei and utilizes the full range of auditory processing capabilities of the neocortex (for review, see Brugge and Reale, 1985). This allows the thalamo-cortico-amygdala system to provide the amygdala with elaborate auditory representations. While either system is adequate for the processing of simple, undiscriminated stimuli, the thalamo-amygdala system is incapable of mediating emotional learning where complex stimuli serve as the CS. For example, during differential Pavlovian conditioning procedures, which require discrimination between a CS paired with the US and a CS that is not paired, the thalamocortico-amygdala pathway is necessary (Jarrel et al., 1987). However, in spite of its advantages in terms of the breadth and accuracy of stimulus representation, the thalamo-cortico-amygdala projection is longer by several synaptic links. Therefore, the direct, thalamo-amygdala projection has a temporal processing advantage that may be adaptive in threatening situations requiring rapid responses to acoustic events (LeDoux, 1986, 1991).

Thalamo-amygdala and thalamo-cortico-amygdala transmission routes converge in the lateral nucleus of the amygdala (LeDoux el al., 1991) and may have complementary functions, trading off speed of transmission against accuracy of representation. Increased knowledge of the organization and function of these complementary pathways is thus necessary to understand 
fully stimulus transmission to the amygdala during emotional processing and associative learning.

\section{References}

Aggleton JP, Burton MJ, Passingham RE (1980) Cortical and subcortical afferents to the amygdala of the rhesus monkey (Macaca mulatta). Brain Res 190:347-368.

Aitkin LM (1973) Medial geniculate body of the cat: responses to tonal stimuli of neurons in medial division. J Neurophysiol 36:275-283.

Aitkin LM, Dunlop CW (1969) Inhibition in the medial geniculate body of the cat. Exp Brain Res 7:68-83.

Aitkin LM, Webster WR (1972) Medial geniculate body of the cat: organization and responses to tonal stimuli of neurons in ventral division. J Neurophysiol 35:365-380.

Amaral DG (1987) Memory: anatomical organization of candidate brain regions. In: Handbook of physiology, Sec 1, The nervous system, Vol V, Higher functions of the brain (Plum F, ed), pp 211-294. Bethesda, MD: American Physiological Society.

Arnault P, Roger M (1990) Ventral temporal cortex in the rat: connections of secondary auditory areas $\mathrm{Te} 2$ and Te3. J Comp Neurol 302:110-123.

Blanchard DC, Blanchard RJ (1972) Innate and conditioned reactions to threat in rats with amygdaloid lesions. J Comp Physiol Psychol 81:281-290.

Bouton ME, Bolles RC (1980) Conditioned fear assessed by freezing and by the suppression of three different baselines. Anim Learn Behav $8: 429-434$.

Brugge J, Reale RA (1985) Auditory cortex. In: Cerebral cortex, Vol 4, Association and auditory cortices (Peters A, Jones EG, eds), pp 229-328. New York: Plenum.

Calford MB (1983) The parcellation of the medial geniculate body of the cat defined by the auditory response properties of single units. $J$ Neurosci 3:2350-2365.

Calford MB, Webster WR (1981) Auditory representation within principal division of cat medial geniculate body: an electrophysiological study. J Neurophysiol 45:1013-1028.

Clerici WJ, Coleman JR (1990) Anatomy of the rat medial geniculate body: I. Cytoarchitecture, myeloarchitecture, and neocortical connectivity. J Comp Neurol 297:14-31.

Deacon TW, Eichenbaum H, Rosenberg P, Eckmann K (1983) Afferent connections of the perirhinal cortex in the rat. J Comp Neurol 220:168-190.

Diamond IT (1983) Parallel pathways in the auditory, visual and somatic systems. In: Somatosensory integration in the thalamus (Macchi G, Rustioni A, Spreafico R, eds), pp 251-272. Amsterdam: Elsevier.

DiCara L, Braun JJ, Pappas B (1970) Classical conditioning and instrumental learning of cardiac and gastrointestinal responses following removal of neocortex in the rat. J Comp Physiol Psychol 73:208-216.

Fanselow MS, Bolles RC (1979) Naloxone and shock-elicited freezing in the rat. J Comp Physiol Psychol 93:736-744.

Gentile CG, Jarrel TW, Teich A, McCabe PM, Schneiderman N (1986) The role of amygdaloid central nucleus in the retention of differential Pavlovian conditioning of bradycardia in rabbits. Behav Brain Res 20:263-273.

Goldberg JM, Neff WD (1961) Frequency discrimination after bilateral ablation of cortical auditory areas. J Neurophysiol 24:119-128.

Graybiel AM (1973) The thalamo-cortical projection of the so-called posterior nuclear group: a study with anterograde degeneration methods in the cat. Brain Res 49:229-244.

Guldin WO, Markowitsch HJ (1983) Cortical and thalamic afferent connections of the insular and adjacent cortex of the rat. J Comp Neurol 215:135-153.

Herbert H, Aschoff A, Ostwald J (1991) Topography of projections from the auditory cortex to the inferior colliculus in the rat. J Comp Neurol 304:103-122.

Herzog AG, Van Hoesen GW (1975) Temporal neocortical afferent connections to the amygdala in the rhesus monkey. Brain Res 115: $57-69$.

Hitchcock J, Davis M (1986) Lesions of the amygdala but not of the cerebellum or red nucleus block conditioned fear as measured with the potentiated startle paradigm. Behav Neurosci 100:11-22.
Iwata J, LeDoux JE (1988) Dissociation of associative and nonassociative concommitants of classical fear conditioning in the freely behaving rat. Behav Neurosci 102:66-76.

Iwata J, LeDoux JE, Meeley MP, Arneric S, Reis DJ (1986) Intrinsic neurons in the amygdaloid field projected to by the medial geniculate body mediate emotional responses conditioned to acoustic stimuli. Brain Res 383:195-214

Jarrel TW, Gentile CG, Romanski LM, McCabe PM, Schneiderman N (1987) Involvement of cortical and thalamic auditory regions in retention of differential bradycardiac conditioning to acoustic conditioned stimuli in rabbits. Brain Res 412:285-294.

Jones EG, Powell TPS (1970) An anatomical study of converging sensory pathways within the cerebral cortex of the monkey. Brain 93: 793-820.

Jones EG, Powell TPS (1971) An analysis of the posterior group of thalamic nuclei on the basis of its afferent connections. J Comp Neurol 143:185-216.

Kapp BS, Frysinger RC, Gallagher M, Haselton J (1979) Amygdala central nucleus lesions: effect on heart rate conditioning in the rabbit. Physiol Behav 23:1 109-1117.

Kelly JB (1990) Rat auditory cortex. In: The cerebral cortex of the rat (Kolb B, Tees RC, eds), pp 381-405. Cambridge, MA: MIT Press.

Killackey HP, Ryugo DK (1975) The organization of unspecific thalamic projections to the telencephalon of the rat. Anat Rec 181:393.

Kolb B (1990) Posterior parietal and temporal association cortex. In: The cerebral cortex of the rat (Kolb B, Tees RC, eds), pp 459-471. Cambridge, MA: MIT Press.

Krieg WSJ (1946) Connections of the cerebral cortex in the albino rat. A topography of the cortical areas. J Comp Neurol 84:221-275.

Kudo M, Aitkin LM, Nelson JE (1989) Auditory forebrain organization of an Australian marsupial, the northern native cat (Dasyurus hallucatus). J Comp Neurol 279:28-42.

Lashley KS (1941) Thalamo-cortical connections of the rat's brain. J Comp Neurol 75:67-121.

LeDoux JE (1986) Sensory systems and emotion. Integr Psychiatry 4: 237-248.

LeDoux JE (1991) Information flow from sensation to emotion: plasticity in the neural computation of stimulus value. In: Learning and computational neuroscience (Gabriel M, Moore J, eds), pp 3-5l. Cambridge, MA: Bradford/MLT.

LeDoux JE, Sakaguchi A, Reis DJ (1984) Subcortical efferent projections of the medial geniculate nucleus mediate emotional responses conditioned to acoustic stimuli. J Neurosci 4:683-698.

LeDoux JE, Ruggiero DA, Reis DJ (1985) Projections to the subcortical forebrain from anatomically defined regions of the medial geniculate body in the rat. J Comp Neurol 242:182-313.

LeDoux JE, Sakaguchi A, Iwata J, Reis DJ (1986) Interruption of projections from the medial geniculate body to an archi-neostriatal field disrupts the classical conditioning of emotional responses to acoustic stimuli in the rat. Neuroscience 17:615-627.

LeDoux JE, Ruggiero DA, Forest R, Stornetta R, Reis DJ (1987) Topographic organization of convergent projections to the thalamus from the inferior colliculus and spinal cord in the rat. J Comp Neurol 264:23-146.

LeDoux JE, Farb CF, Ruggiero DA (1990a) Topographic organization of neurons in the acoustic thalamus that project to the amygdala. $J$ Neurosci 10:1043-1054.

LeDoux JE, Cicchetti P, Xagoraris A, Romanski LM (1990b) The lateral amygdaloid nucleus: sensory interface of the amygdala in fear conditioning. J Neurosci 10:1062-1069.

LeDoux JE, Farb CR, Romanski LM (1991) Overlapping projections to the amygdala and striatum from auditory processing areas of the thalamus and cortex. Neurosci Lett 134:139-144.

Locke S (1961) The projections of the magnocellular medial geniculate body. J Comp Neurol 116:179-194.

Lorente de No R (1938) Cerebral cortex: architecture, intracortical projections, motor projections. In: Physiology of the nervous system (Fulton J, ed), pp 291-340. New York: Oxford UP.

Love JA, Scott JW (1969) Some response characteristics of cells of the magnocellular division of the medial geniculate body of the cat. Can J Physiol Pharmacol 47:881-888.

McDonald AJ, Jackson TR (1987) Amygdaloid connections with posterior insular and temporal cortical areas in the rat. J Comp Neurol $262: 59-77$ 
Morest DK (1964) The neuronal architecture of the medial geniculate body of the cat. J Anat 98:611-630.

Morest DK (1965) The lateral tegmental system of the midbrain and the medial geniculate body: study with Golgi and Nauta methods in cat. J Anat 99:611-634.

Morest DK (1975) Synaptic relationship of Golgi type II cells in the medial geniculate body of the cat. J Comp Neurol 162:157-194.

Morest DK, Winer JA (1986) The comparative anatomy of neurons. Homologous neurons in the medial geniculate body of the opossum and the cat. Adv Anat Embryol Cell Biol 97:1-96.

Morrison RA, Dempsey EW (1942) A study of the thalamo-cortical relations. Am J Physiol 135:281-292.

Nauta WJ, Kuypers HGJM (1958) Some ascending pathways in the brainstem reticular formation. In: Reticular formation of the brain (Jasper JJ, ed), pp 3-30. Boston: Little Brown.

Neylon L, Haight JR (1983) Neocortical projections of the suprageniculate and posterior thalamic nuclei in the marsupial brush-tailed possum, Trichosurus vulpecula (Phalangeridae), with a comparative commentary on the organization of the posterior thalamus in marsupial and placental mammals. J Comp Neurol 217:357-375.

Niimi K, Naito F (1974) Cortical projections of the medial geniculate body in the cat. Exp Brain Res 19:326-342.

Ottersen OP, Ben-Ari Y (1979) Afferent connections to the amygdaloid complex of the rat and cat: projections from the thalamus. J Comp Neurol 187:401-424.

Patterson H (1977) An anterograde degeneration and retrograde axonal transport study of the cortical projections of the rat medial geniculate body. $\mathrm{PhD}$ thesis.

Paxinos G, Watson C (1986) The rat brain in stereotaxic coordinates. Sydney: Academic.

Poggio GF, Mountcastle VB (1960) A study of the functional contributions of the lemniscal and spinothalamic systems to somatic sensibility. Central nervous mechanisms in pain. Bull Johns Hopkins Hosp 106:266-316.

Rockel AJ, Heath CJ, Jones EG (1972) Afferent connections to the diencephalon in the marsupial phalanger and the question of sensory convergence in the "posterior group" of the thalamus. J Comp Neurol 145:105-130.

Roger M, Arnault P (1989) Anatomical study of the connections of the primary auditory area in the rat. J Comp Neurol 287:339-356.

Romanski LM (1991) Sensory convergence in the amygdala: the neurobiology of fear conditioning. $\mathrm{PhD}$ thesis. New York: Cornell University Medical College.

Romanski LM, LeDoux JE (1992) Bilateral destruction of perirhinal and neocortical projection targets of the acoustic thalamus does not disrupt auditory fear conditioning. Neurosci Lett, in press.

Russchen FT (1982) Amygdalopetal projections in the cat. II. Subcortical afferent connections. A study with retrograde tracing techniques. J Comp Neurol 207:157-176.

Sananes CB, Davis M (1992) $N$-methyl-D-aspartate lesions of the lateral and basolateral nuclei of the amygdala block fear-potentiated startle and shock sensitization of startle. Behav Neurosci 106:72-80.
Scheel M (1988) Topographic organization of the auditory thalamocortical system in the albino rat. Anat Embryol (Berl) 179:181-190.

Talman WT, Snyder D, Reis DJ (1980) Chronic lability of arterial pressure produced by destruction of $\mathrm{A} 2$ catacholamine neurons in rat brainstem. Circ Res 46:842-853.

Turner B, Herkenham M (1991) Thalamo-amygdaloid projections in the rat: a test of the amygdala's role in sensory processing. J Comp Neurol 313:295-325.

Turner B, Herkenham M (1981) An autoradiographic study of thalamo-amygdaloid connections in the rat. Anat Rec 199:260A.

Turner BH, Zimmer J (1984) The architecture and some of the interconnections of the rat's amygdala and lateral periallocortex. J Comp Neurol 227:540-557.

Turner BH, Mishkin M, Knapp M (1980) Organization of the amygdalopetal projections from modality-specific cortical association areas in the monkey. J Comp Neurol 191:515-543.

Vaughan DW (1983) Thalamic and callosal connections of the rat auditory cortex. Brain Res 260:181-189.

Veening JG (1978) Subcortical afferents of the amygdaloid complex in the rat: an HRP study. Neurosci Lett 8:197-202.

Wepsic JG (1966) Multimodal sensory activation of cells in the magnocellular medial geniculate nucleus. Exp Neurol 15:299-318.

Whitlock DG, Nauta WJH (1956) Subcortical projections from the temporal neocortex in Macaca mulatta. J Comp Neurol 106:183212.

Winer JA, Larue DT (1987) Patterns of reciprocity in auditory thalamocortical and corticothalamic connections: study with horseradish peroxidase and autoradiographic methods in the rat medial geniculate body. J Comp Neurol 257:282-315.

Winer JA, Morest DK (1983) The medial division of the medial geniculate body of the cat: implications for thalamic organization. $J$ Neurosci 3:2629-2651.

Winer JA, Diamond IT, Raczkowski D (1977) Subdivisions of the auditory cortex of the cat: the retrograde transport of horseradish peroxidase to the medial geniculate body and posterior thalamic nuclei. J Comp Neurol 176:387-418.

Winer JA, Morest DK, Diamond IT (1988) A cytoarchitectonic atlas of the medial geniculate body of the opossum, Didelphys virginiana, with a comment on the posterior intralaminar nuclei of the thalamus. J Comp Neurol 274:422-448.

Zilles K, Wree A (1985) Cortex: areal and laminar structure. In: The rat nervous system, Vol 1 (Paxinos G, ed), pp 375-416. New York: Academic.

Zilles K, Zilles B, Schleicher A (1980) A quantitative approach to cytoarchitectonics. VI. The areal pattern of the cortex of the albino rat. Anat Embryol (Berl) 159:335-360.

Zilles K, Wree A, Dausch N (1990) Anatomy of the neocortex: neurochemical organization. In: The cerebral cortex of the rat (Kolb B, Tees RC, eds), pp 113-150. Cambridge, MA: MIT Press. 